\title{
MIDAS
}

Museus e estudos interdisciplinares

3 | 2014

Varia e dossier temático: "Museos y participación biográfica"

\section{Hugues de Varine - As Raízes do Futuro: 0 Patrimônio a Serviço do Desenvolvimento Local}

\section{Graça Filipe}

\section{(2) OpenEdition}

\section{Journals}

Edição electrónica

URL: http://journals.openedition.org/midas/458

DOI: $10.4000 /$ midas. 458

ISSN: 2182-9543

\section{Editora:}

Alice Semedo, Paulo Simões Rodrigues, Pedro Casaleiro, Raquel Henriques da Silva, Ana Carvalho

\section{Refêrencia eletrónica}

Graça Filipe, «Hugues de Varine - As Raízes do Futuro: O Patrimônio a Serviço do Desenvolvimento Local ", MIDAS [Online], 3 | 2014, posto online no dia 12 maio 2014, consultado no dia 22 setembro 2020. URL : http://journals.openedition.org/midas/458; DOI : https://doi.org/10.4000/midas.458

\section{Este documento foi criado de forma automática no dia 22 setembro 2020.}

\section{cc) (†)}

Midas is licensed under a Creative Commons Attribution-NonCommercial-ShareAlike 3.0 International License 


\title{
Hugues de Varine - As Raízes do Futuro: O Patrimônio a Serviço do Desenvolvimento Local
}

\author{
Graça Filipe
}

\section{REFERÊNCIA}

Varine, Hugues de. 2012. As Raízes do Futuro: O Patrimônio a Serviço do Desenvolvimento Local. Tradução de Maria de Lourdes Parreiras Horta. Porto Alegre: Medianiz. 256 páginas, ISBN: 978-85-64713-03-1.

1 A edição em língua portuguesa de As Raízes do Futuro. O Património a Serviço do Desenvolvimento Local, de Hugues de Varine, publicada em 2012, com tradução da museóloga brasileira Maria de Lourdes Parreiras Horta, surge dez anos após a edição original em língua francesa (Les Racines $d u$ Futur. Le Patrimoine au Service du Développement Local, editado em 2002 pela Asdic). Esta edição brasileira da Medianiz, de Porto Alegre, secundou a primeira tradução e publicação estrangeira do livro, em Bolonha, Itália, em 2005.

$2 \mathrm{Na}$ "Apresentação e Agradecimentos», o autor considera-o um livro «marcado por sua data e por sua origem», assumindo «apresentar uma experiência pessoal, única e subjetiva, que é também um testemunho». Considerada a trajetória da vida de Hugues de Varine e a sua multifacetada experiência profissional (desde a década de 1960 até ao presente), aquele aspeto por ele próprio realçado confere, por si só, um especial interesse a este livro. Não só para profissionais e pessoas ligadas ao património natural e cultural, mas para todos aqueles leitores interessados, de um ponto de vista filosófico, ou histórico, ou numa perspetiva experienciada e prática, em questões da cidadania e do desenvolvimento comunitário.

3 De facto, tal como em anteriores livros de Hugues de Varine, o seu percurso profissional e as suas experiências de terreno estão refletidos em As Raízes do Futuro, tendo o autor 
usado como fontes alguns casos em que trabalhou enquanto consultor em desenvolvimento local e comunitário. O livro oferece-nos uma escrita acessível e clara que a extraordinária tradução de Maria de Lourdes Parreiras Horta preservou - mas simultaneamente vigorosa e apoiada numa robusta estrutura de conceitos teóricos e metodológicos. Para Hugues de Varine (p. 23), a escrita «obriga a certo rigor no raciocínio e a uma atenção à expressão, para sermos compreendidos» e o conceito do livro é o de «levar o leitor a tirar o melhor de si mesmo e a evoluir a partir (...) de suas próprias experiências e do capital de saberes que acumulou» (p. 16).

Ao longo dos vários capítulos, as ideias que Hugues de Varine pretende transmitir consubstanciam-se em inúmeros exemplos práticos, a maioria dos quais vivenciados por si, nomeadamente enquanto consultor de desenvolvimento comunitário, com o autor a salientar e a evidenciar por diversas formas que "o ofício de agente de desenvolvimento é essencialmente artesanal e no qual não há duas missões ou dois casos parecidos» (p. 16).

5 Vejamos quais as características mais importantes da estrutura e da metodologia adotadas por Hugues de Varine para comunicar os seus conteúdos e cumprir os objetivos do livro, cuja finalidade «não é convencer, mas suscitar a reflexão e a tomada de posições por parte do leitor» (p. 7). De modo invulgar, apresenta quatro introduções: a metodológica, a ideológica, a pragmática e a política. Os princípios ficam desde logo claramente expostos e o foco deste guia-manual também: o desenvolvimento local, visto da perspetiva do património, que tem um valor em si mesmo e pode constituir recurso fundamental e fator de sustentabilidade, de desenvolvimento, desde que se verifique a participação efetiva e consciente da comunidade que o detém. A trajetória e as experiências profissionais, assim como os trinta 30 anos de trabalhos de campo, são sinteticamente referidos, o que confere à leitura dos capítulos seguintes um enquadramento lógico e realista, ainda que associado a uma dimensão utópica, que, em nosso entender, é inerente ao pensamento de Varine. Outra característica notável de As Raízes do Futuro advém das sete fichas práticas, a primeira das quais - «Clarifique seus conceitos» - inserida junto à «Introdução ideológica».

6 As outras fichas práticas, associadas a vários dos capítulos, servem como autênticas ferramentas de exploração de realidades e de aplicação de conceitos, à medida da experiência de cada utilizador do livro, intitulando-se: «Conheça o seu património»; «Pesquisar novos usos»; «A organização da ação patrimonial»; «O balanço patrimonial»; «Práticas de ação patrimonial»; e «O museu, instrumento de desenvolvimento». Note-se que o capítulo «A economia do património» (p. 225-228), que antecede o de conclusão, está igualmente apresentado como exercício prático para o leitor: sistematiza «questões indispensáveis» segundo «três casos simples de atores locais»: um proprietário privado, uma municipalidade e uma instituição patrimonial. Podemos, portanto, considerar que são oito as fichas práticas de que o leitor dispõe.

7 Quanto aos vários capítulos, a principal característica que consideramos singularizá-los é a sua própria estrutura: cada um tem uma unidade interna, coerente com o respetivo título, alguns tendo o seu teor complementado por fichas práticas; mas a estrutura foi operativamente concebida e, no seu conjunto, os capítulos contêm a base conceptual, teórica e metodológica, que permite usar o livro como manual de reflexão e de experimentação. Os nomes dos capítulos explicitam um plano, uma abordagem fiel ao título geral do livro. Enunciamo-los: «O conhecimento do património»; «Os usos do património»; «A organização da ação patrimonial»; «Práticas da ação patrimonial»; 
«Um instrumento de desenvolvimento: o museu»; «A economia da ação patrimonial»; e «À guisa de conclusão: retorno ao desenvolvimento».

8 As fontes ou casos associados à sua experiência de terreno, de que emana uma fina análise das realidades, encontram-se sistematizados e apresentam-se sob a forma de «fichas referenciais». São oito, correspondendo a três casos do Brasil, dois de França, dois de Portugal e um de Espanha, num âmbito cronológico, abrangendo desde a década de 1970 até à década de 2000, praticamente até à data da presente edição. Parece-nos relevante a estrutura destas fichas, ou seja os campos usados para referenciar os casos analisados: «Título-local»; "O território»; «Descrição de caso»; «O património envolvido»; "A relação com o desenvolvimento»; e «Lições de método» e «Contato».

Conquanto já tenhamos aqui referido alguns dos principais conceitos teóricos e metodológicos presentes no livro, e que o estruturam, passemo-los em revista mais sistematicamente. Embora correndo o risco de os elencar por defeito, recordemos os que foram definidos e contextualizados por Hugues de Varine, tais como: cultura e cultura viva; desenvolvimento local; património como recurso; ação patrimonial; participação da comunidade; valor/valorização do património; museu como instrumento de desenvolvimento; inventário participativo, entre outros. $\mathrm{E}$ as noções que usa ou faz questão de lembrar que apreendeu em certas realidades e no acompanhamento de várias experiências, como por exemplo: função social do museu; educação patrimonial; e museologia libertadora.

10 Aproveitemos para assinalar outra característica, não apenas da publicação em análise, mas da vasta obra escrita em que podemos conhecer e ver refletido o pensamento de Hugues de Varine, para além de o sabermos regular e assiduamente transmitido em múltiplos momentos da sua participação científica e técnica, como investigador social, consultor, conferencista, mediador, facilitador... Como sempre recorda, as suas ideias tiveram uma filiação no pensamento de Paulo Freire e na partilha intelectual que os ligou na década de 1970 e posteriormente na ligação aos seus discípulos. Reconheçamos o papel incontornável, renovador, do seu pensamento, científico, e do seu trabalho, nomeadamente para a museologia contemporânea, na qual Hugues de Varine emerge num afirmado conflito com os modelos tradicionais, protagonizando um desafiante questionamento, que consideramos muito mais contagiante do que possa ser formalmente admitido tanto por parte de algumas organizações e entidades, quanto por parte de autores, investigadores e diversos profissionais das áreas de património, desenvolvimento local e museus.

11 Através da análise crítica e circunstanciada de uma série de casos, maioritariamente vivenciados por Hugues de Varine - em que se destaca o Creusot - o livro, dedicado pelo autor a todos os que, no Brasil e em Portugal, se têm dedicado à gestão sustentável do património, dá a compreender com clareza a complexidade da ação patrimonial, a partir do património como recurso de desenvolvimento local e «valor agregado da história». Sendo um guia imprescindível nestes domínios de trabalho e de exercício de gestão pública ou de cidadania, é igualmente uma obra imperdível para uma reflexão crítica sobre os maus usos do património e as iniciativas que, por ausência de método ou deficiência de estratégia, causam a sua perda e, consequentemente, a destruição de recursos importantes para uma comunidade ou mesmo a nível nacional.

12 Trabalho que antevemos apaixonante, uma biobibliografia de Hugues de Varine (que saibamos, não feita até agora, mas a que certamente algum investigador ou grupo de investigação se dedicará), poderá levar-nos a percorrer o mundo ao longo do último 
meio século, na sua diversidade cultural, para nos ajudar a compreender a evolução conceptual, as mudanças e as formas de uso do que se designa por património(s) na contemporaneidade, em certa medida influenciadas por Varine (ou solidárias com as suas ideias) e operadas, quer através de um variado leque de organizações, entre as quais museus, quer, principalmente, através de pessoas com ligação ao património e que protagonizaram ou contribuíram para projetos comunitários e de desenvolvimento local.

\section{AUTORES}

\section{GRAÇA FILIPE}

Instituto de História Contemporânea - Faculdade de Ciências Sociais e Humanas - Universidade Nova de Lisboa, Portugal, gracafilipe@mail.telepac.pt 